was becoming distorted by idealization, and the abstract, unreal notion of a standard, thought-free 'animal' was supplying a simple contrast to it.

The Stoics, however, carried this process much further, and the Stoic view, which was strongly biased by moral considerations, was the one that St Augustine incorporated into Christian thought. That is why disputants still often rely on it today. (Other Greek thinkers, such as Porphyry, who defended animals, were largely forgotten). For the Stoics, reason played a central part in morals. Reason was the sole basis of duty because it united all rational beings in a supranational community. As far as human life went, this was a noble concept which did much to discredit slavery. But it excluded irrational beings and allowed of nothing intermediate. Stoic theorists therefore argued determinedly that animals could not reason at all. This led them constantly to give strange and distorted definitions both of reason itself and of the various other faculties, such as perception and emotion, that might be brought in to do its work. They thus drove a gratuitous wedge between reason and the rest of the human personality, producing a wide gap that still gives trouble today.

Questions about animals are not, then, just an amusing extra. Their distortion has seriously harmed our thinking. Oversimplification of the moral issue is of course only one aspect of this distortion, but, as Sorabji says, it is one that can scarcely fail to strike us once we notice the confusions that have concealed it. We cannot today treat all our duties, Stoic-fashion, as pure tributes to the rationality of others, still less to their syntactical abilities. The first question we would now naturally ask is, as Jeremy Bentham rightly said, not 'can they speak?' or 'can they reason?' but 'can they suffer?' More widely, the Darwinian continuity that we now recognize between Homo sapiens and other species radically shifts the burden of proof from those who see possible connections to those who deny them a priori.

Sorabji does not offer any simply moral conclusions. He is rightly critical of the rather crude, sweeping 'moral theories' proposed by pro-animal philosophers such as Tom Regan and Peter Singer. But he is sure that the traditional policy of ignoring this issue is not compatible with the kind of moral principles we now live by. We do have to think the matter out afresh. And many scientists, I think, would now agree.

This is an impressive, important and thought-provoking book. It is clearly written and, although much of it deals with the details of Greek thought, the structure is plain and the index is excellent.

Mary Midgley is at $1 A$ Collingwood Terrace, Newcastle-upon-Tyne, NE2 2JP, UK.

\section{On the edge}

\section{Malcolm W. Browne}

A Positron Named Priscilla: Scientific Discovery at the Frontier. By Marcia Bartusiak et al. National Academy Press: 1994. Pp. 348. \$29.95.

ALL too often, omnibus science samplers intended for lay readers consist of breezy, easily digestible chapters on black holes, dinosaur lifestyles, insect navigation, dolphin communication, space travel, ecological issues and the like; they contain precious little to nourish the minds of people interested in the details of physical science, including (perish the thought) a few illustrative equations. A Positron Named Priscilla is a delightful exception, and (for the most part) a pleasure to read.

The whimsical title refers to an experiment conducted in the late 1980 s by Hans Dehmelt at the University of Washington, who succeeded in trapping and immobilizing a single positron using electric and magnetic fields. As he conducted precise measurements of his caged blob of antimatter, Dehmelt named it Priscilla, explaining in his Science paper (as quoted in the book) that "the well-defined identity of this elementary particle is something fundamentally new, which deserves to be recognized by being given a name, just as pets are given names of persons".

Dehmelt's work is described in one of two excellent esssays in this collection by T. A. Heppenheimer - the first on new laboratory implements (such as the scanning tunnelling microscope) that can manipulate single ions, neutral atoms and particles, and the second on the quest by particle physicists for the elusive top quark and the Higgs boson.

Heppenheimer, like the authors of the other eight essays in this collection, starts his discourse with some easily grasped ideas, from which he gently leads the reader into the thickets. The tour takes one through a fascinating labyrinth of interconnected research, historical turning points, personalities and problems, and makes it easier to place new scientific developments into perspective as they come along.

The quality of writing in these sophisticated essays varies; a few of the authors might have remembered that effective prose requires more than merely getting the facts right. A small problem with several chapters is the intrusion of jargon; 'difficult' becomes 'non-trivial' and a number is 'plugged in' rather than 'substituted'. Also, a few writers occasionally try to explain something by merely labelling it. Some of the biochemistry may glaze the eyes of readers confronting a dense alphabet soup of substances known by their three-letter labels - names familiar to specialists but confusing to outsiders.

But most of the book is remarkably lucid. An example of science writing at its best is an essay by Barbara Burke on some of the mathematical tools used to extract signals from mountains of noise. She shows how these tools help to track submarines, catalogue fingerprints, sort out faint radio signals from celestial objects and even reconstruct the primitive and crumbling recording of an original piano performance by Brahms. From such examples she leads the reader into commendably clear explanations of Fourier analysis, and then to a new mathematical entity called the 'wavelet', which, in the hands of an adept, can supposedly "cut the weeds and spare the daisies".

Although many fields of research are ignored, the chosen subjects are compelling because all of them deal with work in progress. Each essay describes conspicuous accomplishments but leaves the disquieting impression that ultimate success is by no means assured.

An essay by Michelle Hoffman about the diabolical tricks devised by the chameleon-like HIV virus to overwhelm a person's immune system, points to some promising potential defences, but also explains why some scientists believe that a cure for AIDS may never be developed.

Indeed, some of the fields may already have hit major obstacles. The demise of the Superconducting Super Collider has dealt a heavy blow to hopes of identifying the Higgs mechanism - a theoretical pillar of the Standard Model and the putative universal giver of mass. And in earthquake forecasting, geologists and seismologists may have to accept that reliable, short-term predictions of earthquakes are intrinsically impossible. It may be that the timing of an earthquake is critically dependent on undetectably small differences in initial conditions that in essence earthquakes are chaotic.

Other fields of research, enriched by new devices, techniques and discoveries, are booming. Marcia Bartusiak offers an exciting glimpse of the astonishing precision of Doppler interferometry in detecting the vibrational modes of the Sun, vibrations that reveal the deep, hidden mechanisms that power stars.

In chemistry, the discovery that carbon atoms can join together as the footballshaped molecules called fullerenes has created a field of investigation as potentially rich as the one that evolved from the discovery of the structure of benzene.

This is a breathtaking overview of some of the most exciting facets of science at the turn of the century, and there's gold to be mined here, whether the reader is a scientific specialist curious about alien fields of research or merely a science buff.

Malcolm W. Browne is a science writer on The New York Times. 